significantly at one and 24 hours after paracentesis. Creatinine clearance fell significantly at 48 hours, and plasma renin activity, an index of intravascular volume, rose after 24 hours. Peripheral oedema did not seem in these patients to protect renal function or to prevent a rise in plasma renin activity. These findings agree with those of Ginès et al, who showed that daily 4-6 litre paracentesis without replacement of albumin resulted in deterioration of renal function and a rise in plasma renin activity. ${ }^{13}$ In another recent study Titó et al found no deterioration in renal function or rise in plasma renin activity after single total paracentesis with an albumin infusion of $6 \mathrm{~g}$ for each litre of ascites removed. ${ }^{14}$

Most patients in these studies had baseline serum creatinine concentrations of less than $115 \mu \mathrm{mol} / 1$ and serum sodium concentrations higher than $130 \mathrm{mmol} / \mathrm{l}$. As a group they would be expected to respond well to diuretic and dietary measures. ${ }^{459}$ Although paracentesis shortened the stay in hospital and reduced costs in the study of Quintero et al, ${ }^{10}$ patients treated with dietary measures and diuretics do not have to be detained in hospital until the ascites disappears. Once an effective diuretic regimen is established without electrolyte derangement patients may be treated as outpatients. In those with hepatic decompensation or recent alcoholic hepatitis longer stays in hospital may be desirable even after treatment by paracentesis. Furthermore, the cost of the albumin replacement must be considered. In our experience the amount of albumin required is $40 \mathrm{~g}$ for a paracentesis of 8 litres, at a cost of around $£ 75$.

We think that patients with near normal renal function (serum creatinine concentration less than $115 \mu \mathrm{mol} / \mathrm{l}$ ) and serum sodium concentrations higher than $130 \mathrm{mmol} / \mathrm{l}$ can tolerate large volume paracentesis (up to 8 litres) without replacement of albumin. Clinically important haemodynamic decompensation is unlikely, at least immediately after paracentesis. ${ }^{12} \mathrm{~A}$ fall in creatinine clearance is, however, likely unless albumin is given. ${ }^{12-14}$ When peripheral oedema is present no untoward effects are seen with a single paracentesis of up to 5 litres without replacement of albumin ${ }^{11}$; albumin should be given if more than this is removed or if taps are repeated. In patients without peripheral oedema it is safer to give albumin for all large volume ( 5 litres) or repeated paracenteses. Paracentesis is certainly needed when gross ascites causes respiratory embarrassment, severe discomfort, or breakdown of the skin. Nevertheless, we believe that for most patients with ascites from cirrhosis the judicious use of diuretics remains the best treatment.

When paracentesis is performed complete clearance of the ascites by a single paracentesis is preferable to multiple smaller taps. This avoids continued leakage from the paracentesis site and reduces the chance of infection. In all cases paracentesis should be followed by maintenance treatment with diuretics or fluid restriction in patients who are hyponatraemic to prevent recurrence of the ascites. Renal function and serum electrolyte concentrations should be monitored for at least one week after paracentesis.

Several important questions about paracentesis remain unanswered. For instance, when renal function deteriorates after paracentesis is the deterioration reversible, and if so how long does it take to recover? Does the plasma volume and the renal protective effect of an infusion of albumin persist after 48 hours? Further clinical trials are needed to answer these questions and to examine the possible long term benefits of paracentesis compared with treatment with diuretics.

MARIOS PANOS Clinical Research Fellow

DAVID WESTABY Consultant Physician

ROGER WILLIAMS Director

Liver Unit,

King's College Hospital and School of Medicine and Dentistry,

London SE5 9RS

1 Liebowitz HR. Hazards of abdominal paracentesis in the cirrhotic patient. Part III. NY State J Med 1962;62:2223-9.

2 Summerskill WHJ, Baldus WP. Ascites. In: Schiff L, ed. Diseases of the liver. 4th ed. Philadelphia Lippincott, 1975:424-44.

3 Sherlock S, Senewiratne B, Scott A, Walker JG. Complications of diuretic therapy in hepatic cirrhosis. Lancet 1966; i: 1049

4 Sherlock S, ed. Diseases of the liver and biliary system. 7th ed. Oxford: Blackwell, 1985:117-34.

5 Perez-Ayuzo RM, Arroyo V, Planas R, et al. Randomised comparative study of efficacy of frusemide versus spironolactone in non-azotemic cirrhosis with ascites relationship between the diuretic response and the activity of the renin-aldosterone system. Gastroenterology 1983:84: 961-8.

6 Fogel MR, Sawhney VK, Neal EA, Miller RG, Knauer CM, Gregory PB. Diuresis in the ascitic patient: a randomised controlled trial of three regimens. F Clin Gastroenterol 1981;3(suppl): patien:

7 Shear L, Ching S, Gabuzda GJ. Compartmentalization of ascites and edema in patients with hepatic cirrhosis. N Engl f Med 1970;282:1391-6.

8 Epstein $M$. Renal functional abnormalities in cirrhosis; patho-physiology and management. In: Zakim D, Boyer TD, eds. Hepatology: a textbook of liver diseases. Philadelphia: Saunders, 1982:453

9 Pockros PJ, Reynolds TB. Rapid diuresis in patients with chronic liver disease: the importance of peripheral oedema. Gastroenterology 1986;90:1827-33.

10 Quintero E, Gines PO, Arroyo V, et al. Paracentesis versus diuretics in the treatment of cirrhotics with tense ascites. Lancet 1985; i:611-2.

$11 \mathrm{Kao} \mathrm{HW}$, Rakov NE, Savage E, Reynolds TB. The effect of large volume paracentesis on plasma volume-a cause of hypovolaemia? Hepatology 1985;5:403-7.

12 Simon DM, McCain JR, Bonkovski HL, Wells JO, Hartle DK, Galambos JJ. Effects of therapeutic paracentesis on systemic and hepatic hemodynamics and on renal and hormonal function. Hepatology 1987;7:423-9.

13 Ginès $\mathrm{P}$, Titó LI, Panès J, et al. Paracentesis versus paracentesis plus intravenous albumin in the treatment of ascites. Preliminary results of a comparative study. I Hepatol [suppl] 1986;3:23.

4 Titó LI, Ginès P, Panès J, et al. Total paracentesis plus intravenous albumin infusion in the treatment of cirrhotics with tense ascites. J Hepatol [suppl] 1987;5:67.

\title{
Small is hard as well as beautiful
}

\section{Encouragement rather than growth hormone}

There is a good chance that in the American election the taller candidate will win: schoolchildren associate taller people with more prestigious occupations. ${ }^{1}$ Already 5 year olds have stereotypes based on physical appearance. ${ }^{2}$ Small people find it hard to build up public reputation and gain respect because social attitudes reflect traditional stereotypes of their low stature. Adults find it hard to learn alternative ways to react when faced with an appealing small child. ${ }^{3}$

Various behaviour patterns such as dependency, lack of aggressiveness and competitiveness, clowning, and social withdrawal have been associated with small stature. These are best seen as strategies for coping, and they reflect both the children's skills and the pressures they experience.

Specific causes of small stature are associated with differing problems. ${ }^{4}$ Children with hypopituitarism elicit protective responses as their babyish facial features induce caring. They experience specific learning difficulties, which may be secondary to cognitive deficits. Girls with Turner's syndrome have poor visuospatial organisation. In children with familial short stature the family response will be affected by the problems experienced by the parents. The children whose difficulties are the most complex to evaluate are those with 
"environmental"' growth delay (non-organic failure to thrive). Intellectually they often have depressed intelligence quotients and language disorders. Their behaviour may be bizarre, and their views of themselves are often extremely poor.

There seem to be no specific differences between the behaviour patterns of boys with constitutional delay and growth hormone deficiency. ${ }^{5}$ Age is the most important factor influencing the children's difficulties. As puberty approaches the importance of stature increases, especially among boys. ${ }^{1}$ The growth spurts of peers emphasise height differences, and peer pressures for group identification may be associated with the exclusion of small children. They become isolated but not through general lack of social skills ${ }^{6}$ (except for some girls with Turner's syndrome who may have more difficulty in understanding social cues $\left.^{4}\right)$. At this time small children are most vulnerable, and their academic performance deteriorates before recovering in later adolescence. ${ }^{6}$ Greater attention to physical characteristics coupled with greater attention to internal physical states by those who care for them increases the distress. ${ }^{7}$ Increased self awareness often leads to negative self evaluations.

In our response to small children we need to maximise their resources and maintain expectations that are appropriate for age rather than height. The aim is to foster their autonomy and facilitate a sense of their own capabilities. They must be helped to live with their predicament in a positive manner; they must not be allocated the sick role. This means making demands that stretch their capabilities, which are likely to be commensurate with age rather than height. Psychological investigations may help clarify specific learning difficulties.
Small children may be taught ways of coping with the social pressures of adolescence as puberty approaches. We need to question the value that society places on size rather than to contemplate using growth hormone more. Programmes to reduce bullying ${ }^{8}$ suggest that initiatives directed at social processes in schools may create a better climate for the psychological growth of these children. ${ }^{9}$ Resilience does not lie in avoiding stress but rather in encountering it in a way that allows self confidence and social competence to increase through mastery and appropriate responsibility. ${ }^{10}$

Consultant,

SIMON R WILKINSON

Department of Child Psychiatry,

Ullevål Sykehus,

0407 Oslo 4,

Norway

\footnotetext{
Morrow J. Deviational salience; application to short stature and relation to perception of adolescent boys. Percept Mot Skills 1984;59:623-33.

2 Lerner RM, Korn SJ. The development of body build stereotypes in males. Child Dev 1972;43 908-20.

3 Dorner S, Elton A. Short, taught and vulnerable. Special Education 1973;62:12-6.

4 Skuse D. The psychological consequences of being small. F Child Psychol Psychiatry 1987;28: $641-50$.

5 Holmes CS, Hayford JT, Thompson RG. Personality and behavior differences in groups of boys with short stature. Children's Health Care 1982;11:61-4.

6 Holmes CS, Karlsson JA, Thompson RG. Social and school competencies in children with shor stature: longitudinal patterns. f Dev Behav Pediatr 1985;6:263-7.

Mechanic D. Adolescent health and illness behavior: review of the literature and a new hypothesis for the study of stress. $\mathcal{F}$ Human Stress 1983;9:4-13.

8 Olweus D, Roland E. Mobbing: bakgrunn og tiltak (Bullying: background factors and approaches). Oslo: Kirke-og Undervisnings Departement, 1983.

9 Olwens D. Schoolyard bullying - grounds for intervention. School Safety 1987 Fall:4-11

10 Rutter M. Resilience in the face of adversity: protective factors and resistance to psychiatric disorder. Br f Psychiatry 1985;147:598-611.
}

\section{Vascular disease, thrombosis, and recurrent abortion}

\section{May be linked by antibodies against phospholipids}

In the past few years a clinical syndrome has been defined that links venous thrombosis, recurrent abortion, and unexplained cerebral dysfunction and ischaemic episodes. ${ }^{1-3}$ These clinical observations have been associated with antibodies directed against phospholipids. ${ }^{45}$ These antibodies seem to accelerate thrombosis in some patients-perhaps by their effects on the phospholipids of platelets or endothelial cell membranes. The risk of thrombosis is strong-indeed, for some patients with high antibody titres the risk ratio is higher than that for smoking. ${ }^{6}$

Although the antibodies are directed against various phospholipids, the early research selected cardiolipin as the test antigen-largely because reasonably pure cardiolipin was readily available. ${ }^{2}$ Sensitive and reproducible enzyme linked immunosorbent assays (ELISA) currently make testing for cardiolipin antibody cheap and widely available, ${ }^{7}$ and the assays have largely replaced older cumbersome "coagulation" tests such as the lupus anticoagulant test.

The original observations were made in systemic lupus erythematosus, a disease in which patients have a broad range of antibodies. Some patients with atypical systemic lupus erythematosus (who often failed to meet the classification criteria of the American Rheumatism Association) had recurrent thrombosis and recurrent abortion, and their serum contained phospholipid antibodies often without other autoantibodies. Later it became clear that most patients with this syndrome have little or no other evidence of lupus. The anticardiolipin syndrome-or more correctly the phospholipid antibody syndrome-is now reasonably well defined. ${ }^{3}$
The classic example of a patient with the syndrome is a young woman with a history of recurrent deep vein thrombosis, sometimes associated with the contraceptive pill or with stopping warfarin who then presents with recurrent spontaneous miscarriages. ${ }^{89}$ Other thrombotic events may include axillary, ocular, or renal vein thrombosis and the Budd-Chiari syndrome. ${ }^{10}$ "Several patients with the syndrome develop pulmonary hypertension, ${ }^{12}$ possibly because of episodes of pulmonary thrombosis. Major arterial thrombosis may also occur, especially recurrent strokes, ${ }^{13}$ early myocardial infarction, ${ }^{14}$ is and peripheral arterial occlusion. ${ }^{16}$ Several patients have developed multi-infarct dementia in association with phospholipid antibodies. ${ }^{17}$ Pregnant patients with raised titres of phospholipid antibodies (including the lupus anticoagulant) suffer a high risk of spontaneous abortion, possibly because of placental vessel thrombosis. ${ }^{1819}$ Indeed, some patients have had 10 or more failed pregnancies. Other features of the syndrome include livedo reticularis, ${ }^{20}$ chorea, ${ }^{21}$ and thrombocytopenia, ${ }^{22}$ and some speculate that the antibodies may be associated with disease of the heart valves, ${ }^{23}$ migraine and labile hypertension, ${ }^{20}$ and some myelopathies. ${ }^{24}$

There is a danger of overinterpreting the results of tests for phospholipid antibodies, especially those that give borderline results. It would not be surprising, for example, to find transient rises of antibody titre after certain infections. For this reason attempts to standardise the tests are important. ${ }^{25}$ The reliability of assays will be especially important in epidemiology: the true extent of the anticardiolipin syndrome is unknown, and large studies are in progress in vascular, 